\title{
Macklin Effect and Pneumomediastinum with Cardiac Compression in a Mechanically Ventilated Patient
}

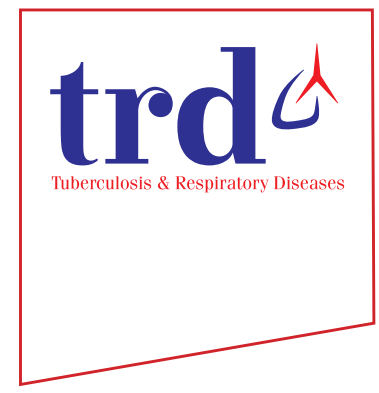

\author{
Tsung-Yeh Tsai, M.D. ${ }^{1}{ }^{\mathbb{D}}$, Jhong-Ru Huang, M.D. ${ }^{1}$, Sheng-Wei Pan, M.D., Ph.D. ${ }^{1,2}{ }^{\mathbb{D}}$, Hsin-Kuo Ko, \\ M.D., Ph.D. ${ }^{1,2}$ and Li-Ing Ho, M.D., ${ }^{1,2}$
}

${ }^{1}$ Department of Chest Medicine, Taipei Veterans General Hospital, Taipei, ${ }^{2}$ School of Medicine, National Yang Ming Chiao Tung University, Taipei, Taiwan

A 51-year-old woman with pneumonia received mechanical ventilation after endotracheal intubation. She developed pneumothorax, which was immediately treated by the placement of a left-side thoracostomy tube. Ethical approval was waived because there was no concern for maintaining the patient's anonymity in the written text and radiographic images. Chest radiography revealed subcutaneous emphysema in the supraclavicular fossae and a lucent stripe outlining the base of the heart, i.e., the continuous diaphragm sign (Fig. 1A), indicating pneumomediastinum. A computed tomography (CT) scan disclosed right pneumothorax with radiographic deep sulcus (Fig. 1B), air dissection along the bronchovascular sheath in the perihilar area, suggesting the Macklin effect (Fig. 1C, D), and pneumomediastinum with extensive gas collection in the pre-cardiac area (Fig. 1E), causing cardiac compression and displacement. After inserting a right thoracostomy tube, adjusting the ventilator settings and using high oxygen concentrations, the patient recovered from barotrauma without progression to life-threatening pneumomediastinum. Finally, she was liberated from mechanical ventilation and discharged. A follow-up CT scan revealed that the heart had returned to its normal position (Fig. 1F).

The first important finding was the CT image of pneumo-

Address for correspondence: Sheng-Wei Pan, M.D., Ph.D.

Department of Chest Medicine, Taipei Veterans General Hospital, No.

201, Sec. 2, Shih-Pai Rd., Taipei 11217, Taiwan

Phone: 886-2-2875-7456, Fax: 886-2-2875-7610

E-mail: sanweipan@gmail.com

Received: Apr. 12, 2021

Revised: Apr. 16, 2021

Accepted: Apr. 20, 2021

Published online: Jun. 17, 2021

(c) It is identical to the Creative Commons Attribution Non-Commercial License (http://creativecommons.org/licenses/by-nc/4.0/). mediastinum with significant cardiac compression ${ }^{1}$. The second was the compatible radiographic findings of the Macklin effect ${ }^{2}$. In our patient, there was obvious air dissection along the peribronchial and perivascular sheaths. This may have indicated that there was increased alveolar pressure causing barotrauma with released air migrating through the bronchovascular sheath to the mediastinum, which is known as the Macklin effect ${ }^{3}$. Hence, ventilator-induced barotrauma was likely the cause of pneumomediastinum in our case. To decrease barotrauma in this mechanically ventilated patient, the ventilator settings should be adjusted to prevent further alveolar overdistention. More importantly, the use of negativepressure thoracostomy tube drainage may reestablish negative intra-pleural pressure and accelerate the resolution of barotrauma. As highlighted by these findings, in mechanically ventilated patients with barotrauma, pneumomediastinum should always be investigated and evaluated for cardiac compression, which warrants early management for a successful resolution.

\section{Authors' Contributions}

Conceptualization: Tsai TY, Huang JR, Pan SW, Ko HK. Formal analysis: Tsai TY, Huang JR, Pan SW, Ko HK. Investigation: Pan SW, Ho LI. Writing - original draft preparation: Tsai TY, Huang JR, Pan SW, Ko HK. Writing - review and editing: Tsai TY, Pan SW. Approval of final manuscript: all authors.

\section{Conflicts of Interest}

No potential conflict of interest relevant to this article was reported. 

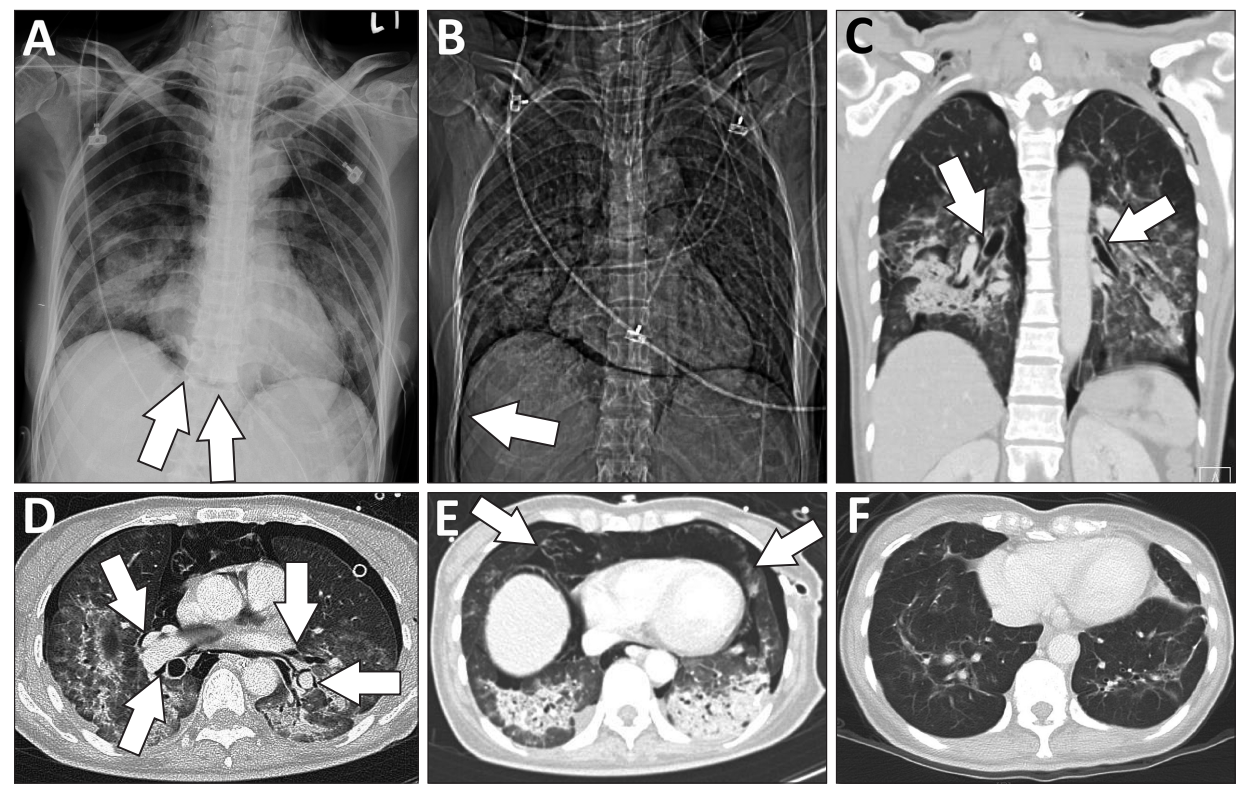

Figure 1. (A) Chest radiograph revealed pulmonary consolidation and a lucent stripe outlining the base of the heart, i.e., the continuous diaphragm sign, indicating pneumomediastinum (arrows). (B) In addition to the continuous diaphragm sign, the deep sulcus sign (arrow) was evident in the corresponding chest computed tomography (CT) scan. (C, D) Lung window CT image showed air dissection along the bronchovascular sheath (arrows) in the perihilar area, suggesting the Macklin effect. (E) CT also revealed pneumomediastinum with extensive gas collection in the pre-cardiac area (between arrows), causing cardiac compression and displacement of the heart. (F) A follow-up CT scan revealed that the pneumomediastinum was resolved and the heart returned to its normal position after discharge.

\section{Funding}

No funding to declare.

\section{References}

1. Obeso Carillo GA, Barge Caballero G, Canizares Carretero MA. The Earth-Heart sign: a new diagnostic finding in a patient with tension pneumomediastinum. Lancet
2014;383:486.

2. Murayama S, Gibo S. Spontaneous pneumomediastinum and Macklin effect: overview and appearance on computed tomography. World J Radiol 2014;6:850-4.

3. Macklin MT, Macklin CC. Malignant interstitial emphysema of the lungs and mediastinum as an important occult complication in many respiratory diseases and other conditions: an interpretation of the clinical literature in the light of laboratory experiment. Medicine 1944;23:281-358. 